\title{
Cognitive activities modulate cerebral hemovelocities
}

\author{
MARY C. SCHMELZEIS and A. E. ROBERTS \\ Catawba College, Salisbury, North Carolina \\ and \\ WILULAM M. MCKINNEY \\ The Bowman Gray School of Medicine, Winston-Salem, North Carolina
}

\begin{abstract}
We report three studies in which one of three cerebral arteries (MCA, ACA, or PCA) was insonated while subjects remembered sets of three letters, made decisions that were based on ethics and itemevaluation scenarios, and solved problems (anagrams, constructed new words from the letters of a target word, mathematics). Accelerations in blood flow velocity occurred during the cognitive tasks, but specific changes were bound to (1) the cerebral artery that was insonated $\left(\mathrm{V}_{\mathrm{MCA}}\right.$ and $\mathrm{V}_{\mathrm{ACA}}$ showed identical modulations during the tasks, but $\mathrm{V}_{\mathrm{PCA}}$ was not affected); (2) the specific task that was provided (only the letter-recall and math tasks sustained accelerations throughout the cogitation period); (3) the mode of task presentation (visually presented tasks led to stronger accelerations initially than tasks presented verbally); and (4) whether the subjects completed the task requirement during the cogitation period, in which case velocity decelerated to baseline levels.
\end{abstract}

Transcranial Doppler (TCD) neuroimaging is a noninvasive technique in which ultrasound is used to measure blood flow velocity in cerebral arteries. TCD monitors ongoing velocity changes rapidly, directly, and continuously, and it is well suited for functional tests that produce rapid changes in cerebral perfusion (Ringelstein, 1989). TCD measures thus can provide important diagnostic information about the presence of intracranial cerebral vascular dysfunctions (Aaslid, 1986).

Droste and associates recently demonstrated that cognitive demands on the cerebral vascular system induce changes in hemovelocity. TCD recorded bilateral accelerations in blood flow velocity (V) in the middle cerebral artery (MCA), relative to baseline (BL), during cognitive activities (e.g., reading abstract four-syllable nouns aloud; Droste, Harders, \& Rastogi, 1989a). Droste, Harders, and Rastogi (1989b, Experiment 1) found that spoken performance of a reading task produced faster bilateral $\mathrm{V}_{\mathrm{MCA}}$ than did silent performance of the task. O'Dell, Roberts, and McKinney (1992b) obtained bilateral accelerations in $\mathrm{V}_{\mathrm{MCA}}$ during three "remembering" activities: recalling letters, generating and maintaining images of personal experiences, and recalling answers to general-knowledge questions. O’Dell, Roberts, and McKinney (1992a) subsequently found that remembering letters and a problemsolving task increased $\mathrm{V}_{\mathrm{MCA}}$ bilaterally, but a decisionmaking task only had transitory effects on $\mathrm{V}_{\mathrm{MCA}}$.

M.C.S. is now at Memphis State University, Memphis, TN. Address correspondence to A.E. Roberts, Department of Psychology, Catawba College, Salisbury, NC 28144 (e-mail: aroberts@catawba.edu).
Velocity measures between hemispheres were statistically comparable during the tasks used in Droste and O'Dell's studies. However, Harders, Laborde, Droste, and Rastogi (1989, Experiment 1) reported that the right-side $V_{M C A}$ was faster than the left-side $V_{M C A}$ for right-hemisphere tasks (e.g., spatial imagination). Reliable differences in measures due to side did not occur with left-hemisphere tasks (e.g., finding nouns). Hemispheric differences in $\mathrm{V}_{\mathrm{MCA}}$ also occur when listening to music-vocal compared to instrumental (Njemanze, 1991). Other than these probe-specific results, velocity measures have not been linked to hemispheric dominance, as indexed by subject handedness (Droste et al., 1989a; Harders et al., 1989). Moreover, hemispheric differences in velocity measures obtained at rest typically are not statistically different (Sorteberg, Langmoen, Lindegaard, \& Nornes, 1990).

The TCD technique as a means to study cerebral hemovelocity modulations during thinking is a relatively new advance in neuroimaging, and several lines of investigation await attention. One is to extend the range of arteries sampled beyond the MCA, which has received most of the research attention. The posterior cerebral artery (PCA) has been sampled during retinal stimulation procedures (see Aaslid, 1987; Gomez, Gomez, \& Hall, 1990) and while subjects viewed pictures (Harders et al., 1989, Experiment 2), but changes in $\mathrm{V}_{\mathrm{PCA}}$ during thinking activities have yet to be documented. Minimal attention has been given to the anterior cerebral artery (ACA) within the context of cognition procedures.

A second line for investigation follows from the first, and it centers on obtaining cerebral hemovelocity measures in these three arteries during comparable sets of 
cognitive tasks. $\mathrm{V}_{\mathrm{MCA}}$ typically is higher than $\mathrm{V}_{\mathrm{ACA}}$, which, in turn, is higher than $V_{P C A}$ (Sorteberg et al., 1990). Whether the responsiveness of these velocities to cognitive activities might be moderated as a result of different BL levels remains an open question.

These two lines of inquiry led to the purpose of the present experiments. TCD measured blood flow velocities in three cerebral arteries (MCA in Experiment 1, ACA in Experiment 2, and PCA in Experiment 3) during identical cognitive tasks. The tasks (recall, decision making, and problem solving) were based on those used by O'Dell et al. (1992a). Separate groups of subjects were used, due to the possibility that TCD measures may be confounded by lessening motivation levels over a session (Droste et al., 1989a).

\section{METHOD}

\section{Subjects}

After giving their informed consent, college students volunteered as subjects. All were experimentally naive regarding TCD procedures, reported no medically diagnosed problems, and were medication free. Experiment 1 included 13 men and 11 women (mean age, 19.4 years; range, 18-21.5 years), and all but 1 were right-handed. Experiment 2 had 11 men and 11 women (mean age, 20.2 years; range, 18-22.5 years), and all but 4 were right-handed. Experiment 3 had 6 men and 9 women (mean age, 21.3 years; range, 20-23 years), and all but 1 were right-handed.

\section{Apparatus \\ A TC2-64B transcranial Doppler unit (Nicolet/EME, Madison, WI) measured blood flow velocity. The MCA was insonated at depths of $50-55 \mathrm{~mm}$ in Experiment 1 with an ultrasound intensity of $100 \mathrm{~mW} / \mathrm{cm}^{2}$, the ACA was insonated at $60-65 \mathrm{~mm}$ (Experi- ment 2), and the $\mathrm{P}_{2}$-segment of the PCA was insonated at 65-70 mm (Experiment 3). The audio signal from the TCD unit was turned off after an insonation was accomplished. The trans- ducer (EME: IMP2L monitoring probe) was secured in a head rib- bon to permit continuous measurement. The unit provided time- averaged mean velocity values every $3 \mathrm{sec}$.}

\section{Procedure}

All the experiments involved three consecutive cognitive phases, each preceded by a 60 -sec BL period. A final 60 -sec BL phase ensued after all phases were completed. Half of the subjects began an experiment with their right MCA insonated, and half began with their left MCA insonated. The three phases were given twice - that is, once under each insonation. The sequence of the phases was counterbalanced for each side, and comparable tasks were offered during the second insonation (the tasks were counterbalanced between sides). Each session required $40-45 \mathrm{~min}$.

Experiment 1: MCA insonated. Each subject was tested with eyes closed while seated in a reclining chair in a dimly lit, soundattenuated room. The MCA was insonated unilaterally, and a 5-min rest period began, the final $30 \mathrm{sec}$ of which provided the BL measures for the first cognitive phase.

In the letter-recall phase, the subjects viewed a set of three consonants printed on a $3 \times 5$ card for $2 \mathrm{sec}$, closed their eyes, and after $15 \mathrm{sec}$ recalled the set in the order presented. Three different sets of consonants were given in this phase.

In the decision-making phase, the subjects responded to each of two ethics-oriented and two item-evaluation scenarios $15 \mathrm{sec}$ after a scenario was read. One ethics-oriented scenario was:

At the end of "Star Trek II," Spock sacrifices his life for the Enterprise, saying "The good of the many outweighs the good of the few." In "Star Trek III," Captain Kirk risks the crew of the Enterprise to help one individual, Spock. Kirk's justification was that "The good of the individual outweighs the good of the many" Who is right, Spock or Kirk, and why?

An item-evaluation scenario was:

You must find an apartment to move into. Given a limited budget, what three factors beside price will influence your decision to rent an apartment? In what order of importance are these factors and why?

The problem-solving phase involved two, five-letter anagramstwo word-construction and two math tasks. A problem was presented, and a 15-sec cogitation period ensued, after which the subject reported a solution. For the anagram and word-construction tasks, the subject viewed the target item for $2 \mathrm{sec}$ and, with eyes closed, generated a solution; that is, the word-construction task required three new words composed of letters from the target word (e.g., chocolate). For the math tasks, the subject was read a problem to solve-for example, "Four men shook hands with each other just once. How many handshakes were made?"

$\mathrm{V}_{\mathrm{MCA}}$ measures were not recorded during instructions, viewing of target problems, or while the subjects answered at the end of a task. The subjects were not permitted to ask questions during the cogitation periods.

Experiment 2: ACA insonated. The procedures of Experiment 1 were continued, but (1) the redundancy in the tasks within phases was eliminated (e.g., only one set of consonants was given in the letter-recall phase), and (2) the cogitation period was extended from $15 \mathrm{sec}$ to $24 \mathrm{sec}$.

Experiment 3: PCA insonated. The procedures of Experiment 2 were followed, but the letter-recall phase included two tasks so that visual and verbal presentations of tasks could be compared. The subjects viewed the letters to be remembered (as in the earlier procedure), but they also had a different set of letters read to them while their eyes were closed.

Table 1

Mean Cerebral Blood Flow Velocities (Centimeters per Second) Obtained During the Seven Phases of the Three Experiments

\begin{tabular}{|c|c|c|c|c|c|c|c|c|c|c|c|c|c|}
\hline \multicolumn{14}{|c|}{ Phases } \\
\hline \multicolumn{2}{|c|}{ BL } & \multicolumn{2}{|c|}{$\begin{array}{l}\text { Letter } \\
\text { Recall }\end{array}$} & \multicolumn{2}{|c|}{ BL } & \multicolumn{2}{|c|}{$\begin{array}{l}\text { Decision } \\
\text { Making }\end{array}$} & \multicolumn{2}{|c|}{ BL } & \multicolumn{2}{|c|}{$\begin{array}{c}\text { Problem } \\
\text { Solving }\end{array}$} & \multicolumn{2}{|c|}{ BL-T } \\
\hline$M$ & $S D$ & $M$ & $S D$ & $M$ & $S D$ & $M$ & $S D$ & $M$ & $S D$ & $M$ & $S D$ & $M$ & $S D$ \\
\hline \multicolumn{14}{|c|}{ Bilateral MCA } \\
\hline 60.7 & 10.44 & 62.6 & 10.56 & 60.5 & 10.72 & 61.4 & 10.66 & 60.6 & 11.42 & 62.5 & 11.52 & 60.5 & 11.68 \\
\hline \multicolumn{14}{|c|}{ Bilateral ACA } \\
\hline 46.0 & 11.38 & 48.5 & 11.41 & 46.9 & 12.00 & 48.2 & 12.32 & 46.7 & 11.09 & 48.4 & 11.80 & 46.1 & 11.58 \\
\hline \multicolumn{14}{|c|}{ Bilateral PCA } \\
\hline 35.4 & 8.64 & 36.6 & 9.36 & 36.5 & 9.86 & 36.6 & 10.06 & 35.6 & 10.37 & 36.1 & 8.86 & 36.7 & 9.92 \\
\hline
\end{tabular}

Note-BL-T refers to the final baseline period given at the completion of the cognitive activities. 


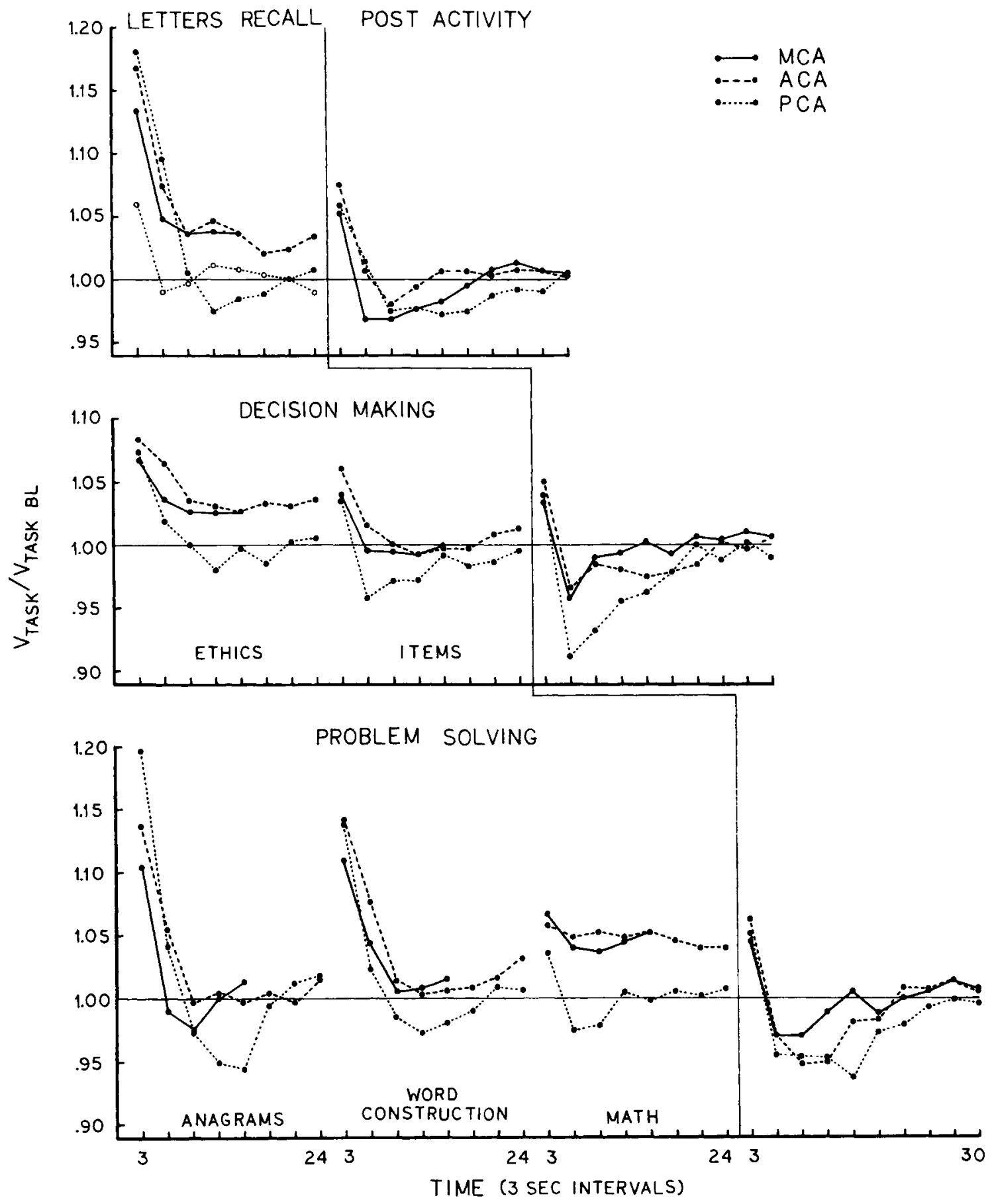

Figure 1. Time course changes in velocity measures during the six cognitive tasks and the 30-sec postactivity period. Two $V_{P C A}$ slopes appear for the letter-recall task-one for visually presented items (filled circles) and the other for verbally presented items (open circles).

\section{Statistical Analysis}

A mean velocity value from each of the separate tasks within the phases was calculated for each subject-that is, sets of 5 values (Experiment 1) and sets of 8 values (Experiments 2 and 3 ). The final $30 \mathrm{sec}$ of each BL (10 values) provided a single mean velocity for that BL. These mean data were analyzed with two-way analyses of variance (ANOVAs), with repeated measures on insonation sides and tasks within a phase. Time course changes in velocities (BL and each interval of a cogitation period) were ana- lyzed with separate repeated measures ANOVAs. Newman-Keuls tests were used for individual comparisons (all alpha levels $=.05$ ).

\section{RESULTS}

The results from the three separate experiments are presented within the contexts of the three cognitive phases for clarity. Table 1 gives the mean velocities in 
BL and each of the cognitive tasks, and Figure 1 shows the time course changes in velocities during the cogitation periods.

\section{Hemovelocity Changes While Recalling Letters}

Separate $2 \times 2$ ANOVAs (with BL and recall as the second repeated measures factors) showed that recalling letters accelerated mean $\mathrm{V}_{\mathrm{MCA}}$ and mean $\mathrm{V}_{\mathrm{ACA}}$ over their BLs $[F(1,23)=36.73$, and $F(1,21)=14.28$, respectively; see Table 1]. A $2 \times 3$ ANOVA on $\mathrm{V}_{\mathrm{PCA}}$ measures (with BL, visual items, and verbal items as the second repeated measures factors) failed to uncover significant differences $(F \mathrm{~s}<1.5)$.

Both $\mathrm{V}_{\mathrm{MCA}}$ and $\mathrm{V}_{\mathrm{ACA}}$ were faster than their BLs throughout the recalling period (see Figure 1) $[F(5,115)=$ $33.76, \eta^{2}=59 \%$, and $F(8,118)=15.81, \eta^{2}=43 \%$, respectively]. Moreover, both velocities were faster in the first recall interval than in the subsequent intervals. $V_{\mathrm{PCA}}$ increased significantly over BL only in the beginning of the recalling period (and into the second interval when the items were viewed). In the first interval of the recalling period, subjects' $\mathrm{V}_{\mathrm{PCA}}$ was significantly faster after seeing the items than after hearing the items.

\section{Hemovelocity Changes While Making Decisions}

Separate $2 \times 3$ ANOVAs (with BL, ethics, and items as the second repeated measures factors) yielded significant differences in mean $\mathrm{V}_{\mathrm{MCA}}$ and mean $\mathrm{V}_{\mathrm{ACA}}[F(2,46)=$ $5.09, \eta^{2}=16 \%$, and $F(2,42)=12.60, \eta^{2}=26 \%$, respectively]. Only the ethics tasks accelerated $V_{M C A}$ and $\mathrm{V}_{\mathrm{ACA}}$ significantly over their BLs. $\mathrm{V}_{\mathrm{PCA}}$ was not significantly affected by the tasks $(F \mathrm{~s}<1)$.

The ethics tasks induced significant accelerations in $\mathrm{V}_{\mathrm{MCA}}$ and $\mathrm{V}_{\mathrm{ACA}}$ over BLs into the fourth interval (the first $12 \mathrm{sec})$ of the decisioning period $[F(5,115)=17.27$, and $F(8,168)=10.63$, respectively]. $\mathrm{V}_{\mathrm{PCA}}$ accelerated over $\mathrm{BL}$ only in the first interval of the period $[F(8,112)=4.07]$.

The item-evaluation tasks significantly increased $\mathrm{V}_{\mathrm{MCA}}$ and $\mathrm{V}_{\mathrm{ACA}}$ over their BLs, but only in the first interval of the period $[F(5,115)=3.99$, and $F(8,168)=$ 4.88 , respectively]. $\mathrm{V}_{\mathrm{PCA}}$ did not change reliably from $\mathrm{BL}$ during the period $(F<1.5)$.

\section{Hemovelocity Changes While Solving Problems}

Separate $2 \times 4$ ANOVAs (with BL, anagrams, word construction, and math as the second repeated measures factors) uncovered significant differences in $\mathrm{V}_{\mathrm{MCA}}$ and $\mathrm{V}_{\mathrm{ACA}}\left[F(3,69)=12.98, \eta^{2}=36 \%\right.$, and $F(3,63)=7.66$, $\left.\eta^{2}=26 \%\right]$. Mean $\mathrm{V}_{\mathrm{MCA}}$ and $\mathrm{V}_{\mathrm{ACA}}$ in the anagram tasks did not differ reliably from their BLs, but both accelerated over their BLs in the word-construction and math tasks. The problem-solving tasks did not affect $\mathrm{V}_{\mathrm{PCA}}$ significantly $\left(F_{\mathrm{s}}<1\right)$.

All three velocities changed significantly from their BLs over the anagram-solving period $\left[\mathrm{V}_{\mathrm{MCA}}, F(5,115)=\right.$ $25.66 ; \mathrm{V}_{\mathrm{ACA}}, F(8,168)=21.05$; and $\mathrm{V}_{\mathrm{PCA}}, F(8,112)=$ 13.67]. All three were faster than $B L$ in the first interval of the period, but decelerated to match $\mathrm{BL}$ in each of the remaining intervals.
$\mathrm{V}_{\mathrm{MCA}}, \mathrm{V}_{\mathrm{ACA}}$, and $\mathrm{V}_{\mathrm{PCA}}$ accelerated significantly over their BLs during the word-construction period $[F(5,115)=$ $24.58, F(8,168)=18.70$, and $F(8,112)=15.40$, respectively]. Both $\mathrm{V}_{\mathrm{MCA}}$ and $\mathrm{V}_{\mathrm{ACA}}$ were faster than their BLs through the third interval of the period (i.e., the first $9 \mathrm{sec}$ ), whereas the acceleration in $\mathrm{V}_{\mathrm{PCA}}$ was confined to the first interval.

Finally, $\mathrm{V}_{\mathrm{MCA}}$ and $\mathrm{V}_{\mathrm{ACA}}$ were significantly faster than their BLs in each interval of the math-solving period $[F(5,115)=18.14$, and $F(8,168)=4.55$, respectively $]$. The math task did not significantly change $\mathrm{V}_{\mathrm{PCA}}$ from the BL measure $(F<1.8)$.

\section{Other Hemovelocity Changes During the Experiments}

$\mathrm{V}_{\mathrm{MCA}}$ was reliably faster in the left side than in the right side in each of the three cognitive phases [all $F \mathrm{~s}(1,23)>$ $5.80]$, but none of the three velocities were significantly affected by a side $\times$ task interaction (all $F \mathrm{~s}<1$ ).

Both $\mathrm{V}_{\mathrm{MCA}}$ and $\mathrm{V}_{\mathrm{ACA}}$ decelerated quickly after the completion of each cognitive phase (i.e., the postactivity periods of Figure 1), and velocities in all three arteries slowed temporarily below their BLs before returning to steady-state levels. Separate $2 \times 4$ ANOVAs on the mean BL values in each experiment (see Table 1) indicated that the BL measures did not change between the three phases (all $F \mathrm{~s}<2$ ). Finally, all differences attributable to gender in the three experiments were unreliable (all $F$ s $<1.5$ ).

\section{DISCUSSION}

We measured hemovelocity in three cerebral arteries (MCA, ACA, and PCA) while subjects performed identical sets of cognitive tasks and found that $V_{M C A}$ and $\mathrm{V}_{\mathrm{ACA}}$ were faster in the thinking periods, but $\mathrm{V}_{\mathrm{PCA}}$ was not. Moreover, the patterns to the changes in accelerations over the thinking period were dynamic rather than static: Velocities were faster in the beginning of the cogitation period, but then decelerated (sometimes to BL levels) within the period.

When we compared the relative responsiveness of the three cerebral arteries, we found that $\mathrm{V}_{\mathrm{MCA}}$ and $\mathrm{V}_{\mathrm{ACA}}$ accelerated in the same tasks (e.g., letter recall, ethics, word construction, and math), and each was relatively unaffected by two tasks - item evaluation and anagrams. Moreover, time course modulations in velocities during the cogitation periods of the tasks followed similar patterns (see Figure 1). On the other hand, our cognitive tasks had minimal effects on $\mathrm{V}_{\mathrm{PCA}}$. These results suggest that the cognitive processing required by our sets of tasks, which were language based (although some were presented visually), are mediated in those regions of the brain irrigated by MCA and ACA collaterals.

$\mathrm{V}_{\mathrm{PCA}}$ is very responsive to retinal stimulation (Aaslid, 1987; Gomez et al., 1990) and viewing (Harders et al., 1989 , Experiment 2) procedures, and the temporary accelerations in $\mathrm{V}_{\mathrm{PCA}}$ probably reflect the procedural requirement of looking at the stimuli (an influence that was 
short-lived). Additional research may show that $\mathrm{V}_{\mathrm{PCA}}$ is more responsive to cognitive tasks predicated on envisioning requirements (e.g., the manipulation of images in a mental rotation task; see Cooper \& Shepard, 1973).

The time course patterns to velocity modulations during thinking show that the degree of initial acceleration varied according to whether the task stimuli were seen or heard, regardless of the artery sampled. Marked increases in velocity followed the three tasks that were given visually: letter recall, anagrams, and word construction $(10 \%-19.8 \%$, across the three arteries). Initial accelerations following the tasks that were given verbally (ethics and item-evaluation scenarios; the math problems), although present, were less pronounced $(3.7 \%-8 \%$, across the three arteries). These initial hypervelocities could be associated with the generalized activation processes in the brain, which are initiated by attending to environmental inputs (Guyton, 1991; Schneider \& Tarshis, 1986). Research into these activation processes has centered on neural components (see Steriade \& McCarley, 1990), but coincident alterations in hemodynamics likely occur within these processes. Subsequent research can confirm whether transitory initial hypervelocity measures are appurtenances to these activation processes.

Modulations in $\mathrm{V}_{\mathrm{MCA}}$ and $\mathrm{V}_{\mathrm{ACA}}$ accelerations in the remainder of the thinking periods apparently depended on whether the subjects disengaged from the task requirement. Velocity accelerations were sustained throughout the letter-recall and math periods, continued through only part of the word-construction and ethics periods, and were not maintained beyond the beginning of the item-evaluation and anagram periods. Many of our subjects later reported that they formed their answers quickly and stopped thinking about the tasks, even though some of the tasks (e.g., item evaluation) were structured to encourage extended deliberation. Their reports, if valid, provide a plausible reason for their velocities' slowing to BL. The cognitive processes that are responsible for rapid resolution of these tasks are more an issue of cognitive research (e.g., Holyoak, 1990), but hemovelocity measures seem to be sensitive correlates to these processes. In short, our data suggest that $\mathrm{V}_{\mathrm{MCA}}$ and $\mathrm{V}_{\mathrm{ACA}}$ accelerations are sustained during a thinking period until (1) a response is called for by an experimenter, or (2) the task is resolved by the subject.

Cognitive activities are known to alter brain activity (e.g., regional cerebral blood flow and metabolism; see Risberg, 1986), but the specific relationships between these brain dynamics and hemovelocity modulations (as indexed by TCD) await specific clarifications. These modulations likely result from diameter changes in arterioles, which occur in response to changes in the metabolic needs of the irrigated tissues (Harders et al., 1989). Postperfusion neuroimaging techniques (e.g., positron emission tomography, or PET) provide information about cognitive brain activity correlates on the basis of metabolic changes, with remarkable spatial resolution. The spatial resolution of TCD is rather circumspect, but
TCD offers excellent temporal resolution. This feature of TCD permits investigation of questions currently beyond the capability of postperfusion methods. The realtime measures given by TCD afford the opportunity to monitor the rapid changes in brain dynamics (e.g., modulations in hemovelocity) that occur in response to cognitive activities as they happen. Moreover, the availability of a technology for obtaining simultaneous bilateral velocity measures (Ferrell, McKinney, Tegeler, \& Myers, 1990) will make successive hemispheric insonations unnecessary and will enhance the utility of the TCD procedure.

\section{REFERENCES}

AASLID, R. (1986). Transcranial Doppler sonography. New York: Springer-Verlag

AASLID, R. (1987). Visually evoked dynamic blood flow response of the human cerebral circulation. Stroke, 18, 771-775.

COOPER, L. A., \& SHEPARD, R. N. (1973). The time required to prepare for a rotated stimulus. Memory \& Cognition, 1, 246-250.

Droste, D. W., Harders, A. G., \& Rastogi, E. (1989a). A transcranial Doppler study of blood flow velocity in the middle cerebral arteries performed at rest and during mental activities. Stroke, 20, 1005-1011.

Droste, D. W., Harders, A. G., \& Rastogi, E. (1989b). Two transcranial studies on blood flow velocity in both middle cerebral arteries during rest and the performance of cognitive tasks. Neuropsychologia, 27, 1221-1230.

Ferrell, W. G., McKinney, W. M., Tegeler, C. H., \& Myers, L. G. (1990, June). Simultaneous bilateral TCD monitoring. Paper presented at the Second International Symposium of Imaging of the Brain in Psychiatry and Related Fields, Würzburg, Germany.

Gomez, S. M., Gomez, C. R., \& HALL, I. S. (1990). Transcranial Doppler ultrasonographic assessment of intermittent light stimulation at different frequencies. Stroke, 21, 1746-1748.

GuYTon, A. C. (1991). Textbook of medical physiology (8th ed.). Philadelphia: Saunders.

HaRders, A. G., LABorde, G., Droste, D. W., \& Rastogi, E. (1989). Brain activity and blood flow velocity changes: A transcranial Doppler study. International Journal of Neuroscience, 47, 91-102.

HolyoaK, K. J. (1990). Problem solving. In D. N. Osherson \& E. E. Smith (Eds.), Thinking: An invitation to cognitive science (Vol. 3, pp. 117-146). Cambridge, MA: MIT Press.

NJEMANZE, P. C. (1991). Cerebral lateralization in linguistic and nonlinguistic perception: Analysis of cognitive styles in the auditory modality. Brain \& Language, 41, 367-380.

O'DeLl, D. M., RoberTs, A. E., \& MCKinNey, W. M. (1992a). TCD neurosonology: A window to view thinking. Bulletin of the Psychonomic Society, 30, 237-240.

O'DeLl, D. M., RoberTs, A. E., \& McKinneY, W. M. (1992b). Transcranial Doppler monitoring of the MCA blood flow velocities during three memory tasks. Journal of Neuroimaging, 2, 186-189.

Ringelstein, E. B. (1989). A practical guide to transcranial Doppler sonography. In J. Weinberger (Ed.), Noninvasive imaging of cerebrovascular disease (pp. 75-121). New York: A. R. Liss.

RISBERG, J. (1986). Regional cerebral blood flow in neuropsychology. Neuropsychologia, 24, 135-140.

SCHNEIDER, A. M., \& TARSHIs, B. (1986). An introduction to physiological psychology (3rd ed.). New York: Random House.

Sorteberg, W., LANGmoen, I. A., LindegaARd, K. F., \& Nornes, H. (1990). Side-to-side differences and day-to-day variations of transcranial Doppler parameters in normal subjects. Journal of Ultrasound in Medicine, 9, 403-409.

STERIADE, M., \& MCCARLEY, R. W. (1990). Brainstem control of wakefulness and sleep. New York: Plenum.

(Manuscript received March 2, 1993; revision accepted for publication April 7, 1994.) 